\title{
FORMAÇÃO CONTINUADA DE PROFESSORES: PRESSUPOSTOS TEÓRICOS SOBRE SUA CONCEPÇÃO E SUAS MODALIDADES
}

\author{
Alexandre Giacomini ${ }^{1}$ \\ Everton Lüdke ${ }^{2}$
}

\begin{abstract}
RESUMO: O conjunto das questões que permeiam a temática da formação continuada de professores apresenta-se, atualmente, como alvo crescente de análises em eventos - encontros, simpósios, congressos etc. - bem como em periódicos nacionais e internacionais. Nesse sentido, o presente artigo, de caráter qualitativo, tem como objetivos: tecer algumas considerações sobre a concepção de formação continuada e discorrer sobre três atuais tendências de modalidades dos processos de formação continuada de professores - reflexão na ação, pesquisa e história de vida - que podem contribuir para a melhoria da prática docente. A metodologia utilizada fundamentou-se na revisão narrativa de literatura. Esperase que esta pesquisa possa oferecer uma contribuição significativa na melhoria dos programas de formação continuada de professores, bem como na qualidade do ensino.
\end{abstract}

Palavras-chave: Formação continuada. Professores. Educação.

\section{CONTINUING EDUCATION OF TEACHERS: THEORETICAL ASSUMPTIONS ABOUT THEIR CONCEPTION AND THEIR MODALITIES}

\begin{abstract}
The set of questions that permeate the theme of continuing teacher education is currently a growing target for analysis in events - meetings, symposia, congresses etc.- as well as in national and international journals. In this sense, the present article, of qualitative character, aims to: make some considerations about the conception of continuous formation and to discuss three current trends in the modalities of continuing teacher education processes - reflection on action, research and life history - that can contribute to the improvement of teaching
\end{abstract}

\footnotetext{
${ }^{1}$ Doutor em Educação em Ciências. Docente do Colégio Militar de Santa Maria, Ministério da Defesa - Exército Brasileiro. Santa Maria, Rio Grande do Sul/ Brasil. E-mail: alexandregiacomini10@gmail.com

2 Ph.D. em Astrofísica e Radioastronomia pela University of Manchester. Docente da Universidade Federal de Santa Maria, Santa Maria, Rio Grande do Sul / Brasil. E-mail: evertonludke@gmail.com
} 
practice. The methodology used was based on the narrative review of literature. It is hoped that this research can make a significant contribution to the improvement of continuing teacher education programs as well as to the quality of teaching.

Keywords: Continued training. Teachers. Education.

\section{FORMACIÓN CONTINUADA DE PROFESORES: PRESUPUESTOS TEÓRICOS SOBRE SU CONCEPCIÓN Y SUS MODALIDADES.}

RESUMEN: El conjunto de las cuestiones que permean la temática de la formación continuada de profesores se presenta, actualmente, como objetivo creciente de análisis en eventos - encuentros, simposios, congresos, etc. - así como en periódicos nacionales e internacionales. En este sentido, el presente artículo, de carácter cualitativo, tiene como objetivos: hacer algunas consideraciones sobre la concepción de formación continuada y discutir tres actuales tendencias de modalidades de los procesos de formación continuada de profesores - reflexión en la acción, investigación e historia de vida - que pueden contribuir a la mejora de la práctica docente. La metodología utilizada se basó en la revisión narrativa de literatura. Se espera que esta investigación pueda aportar una contribución significativa en la mejora de los programas de formación continuada de profesores, así como en la calidad de la enseñanza.

Palabras clave: Formación continuada. Profesores. Enseñanza.

\section{Introdução}

Em anos recentes, entende-se que a educação se insere num ambiente crescentemente complexo, a partir de qualquer lógica, ponto de vista, ou teoria que se escolha. A inclusão de grupos marginalizados tensiona o ambiente escolar, as velhas práticas, os rituais, e requer outras formas de se pensar a educação e a escola. Nesse contexto de mudanças imperativas, é imputado ao professor um papel central como catalisador dessas inovações, porém sem dispor de recursos e de alternativas para dar conta dessa realidade que se apresenta com toda a sua diversidade. De uma formação recebida para trabalhar com públicos homogêneos, o professor passa a trabalhar com grupos cada vez mais heterogêneos, além de lhe ser exigido que desenvolva com seus alunos capacidades de trabalhar em grupo, de resolver problemas, de elaborar, executar e acompanhar projetos, entre outras tantas. 
A formação, pautada no paradigma técnico-científico ${ }^{3}$, já não dá mais conta da preparação desse professor que deve atuar nessa nova realidade. De um tempo de certezas, passamos à constância da incerteza, e é neste tempo e espaço que se situa o professor. Diante dessas problemáticas, a formação continuada de professores tem sido revista, discutida, analisada, tensionada pelos pesquisadores da área.

O conjunto das questões sobre formação continuada de professores apresenta-se como alvo crescente de análises em eventos - encontros, simpósios, congressos etc. - e em periódicos nacionais e internacionais. Nos últimos anos, têm-se testemunhado um retorno dos professores ao centro de interesses das políticas públicas educacionais, conforme aponta Nóvoa $(2009$, p. 2).

Os anos 70 foram marcados pela racionalização do ensino, a pedagogia por objetivos, a planificação. Os anos 80 pelas reformas educativas e pela atenção às questões do currículo. Os anos 90 pela organização, administração e gestão dos estabelecimentos de ensino. Agora, parece ter voltado o tempo dos professores.

Essa ideia também é confirmada por outros estudiosos (ANDRÉ, 2000; ROMANOWSKI, 2002; GATTI; BARRETO, 2009) ao certificar que os pesquisadores, acadêmicos, educadores, políticos da área da educação e associações profissionais envolveram-se com a temática da formação continuada de professores nas últimas décadas. Esse aumento contínuo do interesse pelo tema pode ser constatado por meio do levantamento de pesquisas em teses e dissertações, no banco de dados da Coordenação de Aperfeiçoamento de Pessoal de Nível Superior (CAPES), tanto no período de 1990 a 1998 por André (2000) e Romanowski (2002), como no período de 2006 a 2009 por Gatti e Barreto (2009).

Dessa forma, o presente estudo se torna relevante, pois a passagem para uma visão de educação que se considera mais coerente com teses e propostas epistemológicas

\footnotetext{
${ }^{3}$ A formação do professor, segundo esse paradigma, caracterizou-se pela fragmentação do processo educativo, pela redução do fazer pedagógico ao cumprimento de normas e técnicas, bem como pelo trabalho pouco criativo herdado do positivismo e que esteve presente no período do fordismo/taylorismo (KUENZER, 1999).
} 
contemporâneas passa, incontestavelmente, pela formação continuada de professores, bem como, ampliar as discussões em torno desta temática é necessário e urgente. Diante desse cenário, este artigo tem como objetivos: tecer algumas considerações sobre a concepção de formação continuada; discorrer sobre três atuais tendências de modalidades dos processos de formação continuada de professores - reflexão na ação, pesquisa e história de vida - que podem contribuir para a melhoria da prática docente.

Para alcançar tais objetivos, o estudo, de caráter qualitativo (GIL, 2007), fundamentouse na metodologia da revisão narrativa de literatura. Segundo Bernardo, Nobre e Jatene (2004), as revisões narrativas de literatura são publicações amplas, apropriadas para descrever e discutir o desenvolvimento ou o estado da arte de um determinado assunto, sob ponto de vista teórico ou contextual; além disto, não informam as fontes de informação utilizadas, a metodologia para busca das referências, nem os critérios utilizados na avaliação e seleção de trabalhos.

Corroborando nessa linha, Rother $(2007$, p. 5) aponta que artigos de revisão de literatura:

[...] têm um papel fundamental para a educação continuada, pois permitem ao leitor adquirir e atualizar o conhecimento sobre uma temática específica em curto espaço de tempo", no entanto, eles "não possuem metodologia que permita a reprodução dos dados e nem fornecem respostas quantitativas para questões específicas.

Dessa forma, este trabalho foi desenvolvido a partir de material já elaborado e constituído principalmente de livros, artigos científicos e dados encontrados em sites da Internet, bem como, nas contribuições de vários pesquisadores, estudiosos e autores, caracterizando-se assim num estudo para conhecer as principais concepções científicas sobre o tema.

\section{Concepções que Balizam a Formação Continuada de Professores}

Inicialmente, faz-se necessário tecer algumas considerações sobre a concepção de formação, já que o foco deste estudo abarca a formação continuada de professores. Para isso, buscou-se a autora Bicudo (2003, p. 25), que interroga o significado de formação. Essa 
pesquisadora, ao refletir sobre elementos teóricos de autores de História da Educação Ocidental, põe em relevo a acepção de formação.

Segundo Bicudo (2003, p. 31, grifo da autora) o significado de formação envolve:

[...] a idéia (sic) de perseguir a forma ideal, construída mediante a consciência do modo de vida de um povo, de seus anseios, usos e costumes, códigos de honra, valores prezados, da força que move as pessoas na direção da percepção do dever e que as faz se sentirem orgulhosas pelos seus feitos. Mas nunca assumido, o ideal, como uma forma perfeita que submeta a formação a um modelo que a aprisione dentro de limites rígidos. Ideal tido como o que imprime direção ao movimento. Porém, movimento que se efetua com o que se move, e isso que se move também tem sua força, o que significa que a forma não pode conformar a ação, mas a própria ação, ao agir com a matéria, imprime nela a forma. Há, portanto, um jogo entre ideal, entendido como forma que imprime direção, ação, movida pela força imperante que vigorosamente impele a pessoa para um ato, e que brota do sentimento de dever e de orgulho, por ter conseguido tornar-se o que se tornou, e matéria, constituída pela realidade de vida do povo, que abrange sua historicidade, seus mitos, seus modos de advertir, de impor preceitos, comunicar conhecimentos e aptidões profissionais.

Desse modo, a autora enfatiza que a compreensão de formação está atrelada às interrelações entre forma, ação, matéria determinadas pela lucidez do modo de vida de um povo, revelando valores, ideais, conhecimentos, mitos, práticas de vida e significados.

A partir dessa discussão inicial, dá-se continuidade ao delineamento das compreensões que permeiam a formação de professores. Nesse sentido, é importante, neste momento, optar por uma terminologia adequada ao se referir à formação do educador, a fim de dar prosseguimento nesse estudo teórico e evitar uma carga semântica de termos.

Na Lei de Diretrizes e Bases da Educação Nacional (LDB), Lei no 9.394/96 (BRASIL, 1996), a formação continuada aparece sob várias formas: capacitação em serviço, educação continuada, aperfeiçoamento profissional continuado, programas de capacitação e treinamento em serviço. De acordo com Marin (1995), educação permanente, formação continuada, educação continuada são termos que podem ser colocados na mesma família, uma vez que são correlatos. Apesar de existirem nuances entre esses termos, é possível considerá-los como complementares e não como contraditórios, já que colocam como base da formação de professores o conhecimento que se constitui no suporte das interações que possibilitam a superação dos problemas e das dificuldades. 
Assim, neste trabalho, optar-se-á pela expressão formação continuada, uma vez que ressalta a ideia de um processo permanente de construção, de desenvolvimento e de amplitude do professor, bem como que se insere como elemento de socialização e crescimento pessoal e profissional, capaz de interferir na melhoria de seu trabalho no contexto escolar. Além disso, esse termo escolhido é usado pela maioria dos educadores que apontam para a discussão e/ou para a proposição de projetos que levam em conta um professor inserido em um contexto - social, histórico, político e cultural - que tem como função trabalhar o conhecimento culturalmente acumulado em uma perspectiva transformadora da realidade (MAZZEU, 1998; PIMENTA, 2002; GATTI, 2003; GEGLIO, 2003).

Garcia (1995) aponta uma compreensão para a formação continuada de professores como sendo o conjunto de atividades desenvolvidas pelos professores em exercício com finalidade formativa, realizadas individualmente ou no coletivo, visando tanto ao desenvolvimento pessoal como ao profissional, na direção de prepará-los para a realização de suas atuais tarefas ou outras novas que se coloquem. Para Canário (1998), a formação continuada de professores é vista, segundo uma perspectiva contextualizada, como um processo de formação inacabado e de permanente elaboração e reelaboração desse profissional e de sua construção da identidade. Ela não pode ser entendida apenas segundo uma perspectiva de reciclagem, ou seja, de complementação de estudos da formação inicial. O autor também acrescenta que é no espaço da escola que o professor vai construir sua identidade profissional, por meio de um processo coletivo de formação continuada na qual abarque a prática docente, seus saberes e fazeres, suas experiências e suas necessidades, com o objetivo de proporcionar as mudanças necessárias no tocante a sua profissão, bem como superar deficiências históricas dos modelos de formação.

Nessa mesma linha, Nóvoa (1991) assevera que a escola é vista como locus de formação continuada do professor, pois é nela que o educador constrói e desconstrói sua aprendizagem, troca saberes e experiências, efetua descobertas e articula novas posturas na sua práxis. Nesse sentido, o autor adverte:

A formação continuada deve alicerçar-se numa reflexão na prática e sobre a
prática [...] deve estar articulada com desempenho profissional dos
professores, tomando as escolas como lugares de referência. Trata-se de um
objetivo que só adquire credibilidade se os programas de formação se 
estruturarem em torno de problemas e de projetos de ação e não em torno de conteúdos acadêmicos (NÓVOA, 1991, p. 30).

Conforme Nóvoa (2002), a formação continuada de professores se localiza entre dois arcabouços: o da pessoa do professor - no qual a identidade do docente é construída por meio do esforço investido em si mesmo e pela sua autonomia na busca de um trabalho bem feito - e o da organização escolar e seu projeto educativo - no qual a preocupação com a mudança de paradigma dos professores está atrelada ao contexto das instituições, por meio de programas articulados as suas necessidades formativas. Corroborando nessa discussão, Candau (1996) destaca três pressupostos básicos acerca da formação continuada de professores, que estão em evidência no atual contexto e são considerados pertinentes entre os profissionais da educação. São eles:

1) A escola deve ser vista como locus de formação continuada. Segundo Candau (1996, p. 144): “[...] considerar a escola como lócus de formação continuada passa a ser uma afirmação fundamental na busca de superar o modelo clássico de formação continuada e construir uma nova perspectiva na área de formação continuada de professores."

2) A valorização dos saberes da experiência docente: os balizadores de todo processo de formação continuada têm que levar em consideração o saber, o reconhecimento e a valorização do saber docente.

3) A consideração do ciclo de vida dos docentes: para um adequado desenvolvimento do processo de formação continuada, é necessário levar em consideração as diferentes etapas do desenvolvimento profissional do magistério, tendo em vista que, as necessidades e os problemas decorrentes dos professores na fase inicial, daqueles que possuem mais tempo de experiência e dos que estão no final de carreira são diferentes. Portanto, não se podem oferecer situações de formação padronizadas e homogêneas.

Nesse escopo, o Decreto $\mathrm{n}$ ㅇ. 6.755/2009, no artigo 2ำ, inciso XI incrementa a discussão e aponta a formação continuada "como componente essencial da profissionalização docente, devendo integrar-se ao cotidiano da escola e considerar os diferentes saberes e a experiência docente" (BRASIL, 2009). 
De acordo com Lima (2001), a formação continuada de professores pode estar articulada a dois princípios de concepção marxista: o trabalho como esfera produtora da vida humana e a práxis da atividade docente. Desse modo, Lima (2001, p. 30) entende que a formação continuada é um processo de interdependência entre o conhecimento, a atividade docente e o desenvolvimento profissional do professor, como possibilidade de postura reflexiva catalisada pela práxis. Além disso, para que ela seja confirmada na prática é necessária sua vinculação com a vida, os sonhos e o ofício do professor.

Segundo Freire (1996), a formação continuada de professores está inserida no contexto educacional, a partir das ideias calcadas no educador como sujeito inacabado e em contínuo processo de mudança e transformação de sua prática educativa, bem como, ela deve ser orientada prioritariamente pela reflexão crítica permanente. Nesse sentido, para esse autor, o exercício da reflexão crítica e o permanente movimento de procura pela formação constante/contínua levará o educador a transformar sua prática docente de curiosidade inicialmente ingênua e crítica para epistemológica.

Outro aspecto levantado por Freire (1996), no tocante à formação continuada, é que o professor é um sujeito inerentemente pesquisador, ou seja, a promoção da pesquisa aliada à prática reflexiva crítica é algo que está no seio deste profissional, pois "não há ensino sem pesquisa e pesquisa sem ensino" (p. 32). Desse modo, conforme o autor, é importante que o professor, nessa busca constante pela sua formação permanente e continuada, tenha consciência do que faz e de seu significado, que estabeleça o confronto de como era a situação e como está sendo desenvolvida, e de como é possível reconstruir para fazer coisas diferentes das que sempre fazemos.

Nesse escopo, depreende-se que a formação continuada de professores necessita estar articulada aos fazeres na e da escola, bem como, requer uma formação compartilhada e também pode ser uma autoformação, uma vez que os professores reconstroem os seus saberes e experiências cotidianamente vivenciadas. Ainda, sob esse prisma, os desejos, as intenções pessoais dos professores que os levam a determinadas ações pedagógicas são moldados culturalmente pelos "outros" docentes que convivem no mesmo contexto e que com suas expectativas e práticas se tornam referências, matrizes do desempenho de sua tarefa, o que mostra que esse quefazer, embora traga em si a dimensão da singularidade, 
mescla a dimensão social e é sempre empreitada coletiva. Para colaborar nessa discussão, apresentam-se na próxima seção três atuais tendências de modalidades dos processos de formação continuada de professores que podem contribuir para a melhoria da prática docente.

\section{Processos de Formação Continuada de Professores}

O texto a seguir apresenta os atuais processos de formação continuada de professores: reflexão na ação, a contribuição da pesquisa na formação docente e as contribuições das histórias de vida na formação de professores.

\section{Reflexão na ação}

Uma das formas mais difundidas de formação continuada de professores é a reflexão na ação, em que se destaca a importância do pensamento prático dos professores. Segundo Zeichner (1993), os processos reflexivos exigem atitudes e disposição. Entre as atitudes identificadas estão: mentalidade aberta, responsabilidade e entusiasmo. Nesse modelo, a prática é o eixo central, o ponto de partida da reflexão. A clássica separação entre teoria e prática é superada por uma relação permanente entre elas. A prática constitui mais que um campo de aplicação, é um processo de investigação; o pensamento prático assume uma perspectiva holística, um todo. Ela constitui momento criativo, próprio para invenção, para a diferença.

O pensamento prático não é ensinado, mas pode ser aprendido e geralmente pressupõe a participação dos envolvidos; a intervenção do tutor, do supervisor é de questionamento reflexivo; os centros de formação constituem escolas de desenvolvimento profissional; a valorização da experiência inclui a própria formação do formador. Nesse processo, os métodos de investigação etnográficos e qualitativos podem representar diferenciais de qualidade significativa (ZEICHNER, 1993).

Recomenda-se que a efetivação de processos de formação continuada de professores com base na reflexão seja organizada em "grupos de investigação" para que a prática possa ser refletida na escola, coletivamente. Nesse sentido, Pimenta (2002) alerta que a teoria e a 
prática são inseparáveis na profissionalização docente, os saberes teóricos se articulam aos saberes da prática, ressignificando-os e sendo por eles ressignificados.

Para essa mesma autora, a organização dos grupos colaborativos de investigação da prática envolvendo professores requer condições para a sua implementação, caso contrário constituem discursos ou novos modelos de formação, que serão esvaziados de significação na mudança da ação e profissionalização continuada do professor. As maiores barreiras, segundo Pimenta (2002), para a introdução de um programa de formação continuada de professores de reflexão na e sobre a prática são os saberes e a cultura escolar e a cultura universitária, pois a estrutura de formação tradicional tem sido primeiro fornecer conhecimentos e depois desenvolver a prática.

Nessa visão, é válido sinalizar que os campos teóricos dos processos reflexivos incorporam a experiência como possibilidade de promover mudanças nos sujeitos, uma epistemologia da prática por meio da problematização, análise e reflexão. O conhecimento da ação não a precede, pois está na ação e se torna um hábito; os desafios diferenciados exigem novos modos de ação, os quais necessitam da reflexão sobre a reflexão na ação. Nesse processo, há uma valorização da pesquisa na ação profissional, a reflexão é base para o professor pesquisador de sua prática.

Depreende-se a partir desse escopo, que a produção do saber docente, a partir da prática, precisa superar o praticismo e a individualização; a reflexão por si só é insuficiente para resolver os problemas educativos. Além disso, pode ocorrer uma banalização dos processos reflexivos pela sua simplificação e gerar uma limitação da identidade epistemológica dos processos de formação de professores, por limitar a ação docente aos espaços da sala de aula. É necessário que linguagem, sistema de valores, processos de compreensão e a forma de definição do conhecimento estejam incluídos na pesquisa do professor sobre sua prática.

Para Libâneo (2002), a reflexividade pressupõe:

1) Autoanálise: um voltar-se sobre si mesmo, como se dobrasse o próprio processo de conhecer, é uma tomada de consciência sobre os atos, um conhecimento do conhecimento que se sabe, um pensar sobre si para formar-se, para formar uma teoria e reorientar a própria prática; 
2) A relação entre a reflexão e as situações da prática, não como o início da análise, mas considerando a situação concreta, a experiência pensada com posterior redirecionamento, produzindo a ação-relação entre os atos realizados e as transformações produzidas;

3) Uma realidade que existe e pode ser captada pela reflexão, um esforço para captar o movimento, as relações e nexos para construir uma explicitação do real. Tratase de construção teórica, uma prática-teoria crítica de caráter político, verificando as condições que produzem a alienação, injustiças e relações de dominação, o que exige rigor e crítica.

Segundo Libâneo (2002), o movimento dos anos de 1960, nas associações estudantis, permitiu a formação da consciência crítica dos militantes e impôs rumo à maturidade do conhecimento e da busca de liberdade. Já, durante os anos de 1980, o movimento de reflexão contribuiu para a consciência crítica, por buscar nexos internos e suas relações sociais, além de favorecer a percepção de significados e da diversidade existente no sistema educacional. O autor ainda aponta que as posturas neoliberais dessa época se direcionavam para uma racionalidade instrumental.

Assim, nesse panorama, a postura crítica pressupõe o desenvolvimento de uma reflexão que realiza o distanciamento da prática para vê-la, entendê-la, avaliá-la, incorpora o senso comum sobre as práticas numa perspectiva de apropriação teórico-prática das atividades em contextos concretos da ação docente. A atividade se impõe pela necessidade de pensar sobre ela. O professor na sala de aula necessariamente terá uma ação - a consciência sobre essa ação é que a qualifica para além dela - o que permite perceber seu significado.

\section{A contribuição da pesquisa na formação docente}

Outra perspectiva está em considerar a pesquisa como possibilidade de compreender a prática e constituir indicativos teóricos, ampliando o saber docente. Nesse contexto, a pesquisa atua como possibilidade de profissionalização e autonomia do professor. 
A pesquisa, ao considerar os objetivos da escola, favorece a socialização sistemática do conhecimento científico, integrando as gerações no ideário da sociedade moderna para uma nova cultura, além disto, permite o desenvolvimento de habilidades de investigação e de análise, superando interpretações baseadas no conhecimento tácito. O movimento de valorização da pesquisa na formação de professores, especialmente a chamada investigaçãoação, tem sua origem nos anos 1960, na Inglaterra, nos currículos formulados pelas escolas de inovação. Esse movimento no Brasil, segundo André (2000), ocorreu mais recentemente, no final dos anos de 1980 e intensificou-se na década de 1990. Para essa autora, uma das principais contribuições são as investigações e reflexões sobre: qual é a natureza dos conhecimentos produzidos pela pesquisa? Como é possível formar o professor pesquisador? Que condições o professor tem para realizar a pesquisa?

Os questionamentos realizados por Santos (2001) sobre os dilemas e perspectivas da relação ensino-pesquisa apontam para os seguintes problemas: a pós-graduação foi ampliada, mas não revela contribuições significativas para a melhoria dos recursos de graduação, pois é pequena a relação entre ensino e pesquisa. Nesse enfoque, cabe comentar que nas universidades têm ocorrido o privilégio da pesquisa, que geralmente utiliza a maioria dos recursos existentes, propicia um maior "status" aos pesquisadores; todavia, é urgente que seja priorizada a articulação entre o ensino e a pesquisa, sobretudo nos cursos de formação de docentes.

Schön (1992) indica que o profissional reflexivo elimina a distância entre a pesquisa e a atividade profissional. Argumenta que há seriedade nas reflexões realizadas pelos professores e defende que deve ser abandonada a postura que distingue as reflexões produzidas pelos professores e a pesquisa.

Desse modo, é importante ressaltar que os professores identifiquem os problemas de ensino que vivenciam no seu cotidiano e procurem propostas de solução existentes na literatura. Além disso, destaca-se que em suas experiências, os docentes possam colocar em ação as alternativas planejadas e possam corrigir os desvios se utilizarem a observação e reflexão. Portanto, a pesquisa ajuda a encontrar soluções e a lidar com pressupostos e representações, torna o professor um produtor do conhecimento e não apenas consumidor, bem como, gera uma descrição como conhecimento teórico a partir do conhecimento prático. 
Os estudos realizados por Zeichner (1993) sobre a formação reflexiva de professores procuram induzir os mestres a realizarem análise crítica da prática, como participantes de projetos de pesquisa, por meio de estudos etnográficos e da pesquisa-ação, que privilegia os estudos de casos. As preocupações de Perrenoud (1993) apontam para as questões relacionadas ao tipo e finalidade da pesquisa na formação inicial. Indica que a pesquisa pode favorecer a participação dos futuros professores em investigações, realizando o confronto de dúvidas e incertezas com a apropriação dos conceitos. Segundo o autor, a pesquisa desenvolve habilidades como: motivação, curiosidade, vontade de encontrar explicações, constatação de que as necessidades são de natureza complexa e reflexão sobre a tomada de decisão.

Nesse horizonte, é importante considerar que a prática reflexiva não pode ser considerada metodologia de pesquisa, ou seja, não se trata do desenvolvimento de professores pesquisadores, mas de trabalhos conjuntos entre professores e pesquisadores em que é possível empreender o refinamento de suas metodologias de pesquisa e de ensino, compartilhar problemas e encontrar alternativas de encaminhamentos. Sacristán (1998) indica como aspectos a serem consideradas na realização da pesquisa as condições de trabalho e a formação cultural do professor. Para o autor, o problema da formação para a pesquisa é muito mais complexo, pois os conhecimentos construídos ao longo dos cursos de formação não contribuem para a intensificação do pensar. Dessa forma, recomenda-se que os professores incorporem em seu cotidiano e na prática docente a realização constante da pesquisa e a tornem uma cultura de investigação.

As análises realizadas por Charlot (2006) indicam que a pesquisa educacional não entra na sala de aula, e não é direcionada para estabelecer a relação teoria-prática; os professores não estão em contato com a universidade e acham a pesquisa um processo que demanda muito tempo e esforço sem resultados efetivos para melhorar a prática pedagógica, o que gera o afastamento da pesquisa na sala de aula. Destaca diferenças entre o ensino e a pesquisa, em seus fins e métodos, tais como: o ensino é global, a pesquisa analisa, o ensino tem objetivos a serem realizados. O professor decide imediatamente em sala de aula sem tempo suficiente para refletir.

Soares (2001) ressalta que os professores, ao realizarem pesquisa, apreendem e 
aprendem processos de produção do conhecimento. Destaca que a investigação faz parte de qualquer atividade, o que não significa construir-se pesquisa em sentido estrito. No entanto, pondera sobre a necessidade de formar um docente inquiridor, questionador, que problematiza criticamente a sua prática, para o desenvolvimento de uma atitude ativa, autônoma, criativa e comprometida. O papel da "pesquisa" não é dizer o que o professor deve fazer, mas ajudá-lo a melhor entender o que está acontecendo na sala de aula.

Do conjunto dessas reflexões é possível depreender que a integração entre ensino e pesquisa favorece a melhoria da formação docente, mas a pesquisa acadêmica não altera o estado atual das coisas, além de não ser a única forma de qualificar um profissional. Esse movimento colocou novas perspectivas no campo da ação docente, em que investigar, questionar, confrontar é necessário independente de se atribuir o rigor da pesquisa a esse tipo de atividade do professor.

É importante frisar que o professor pesquisador que prioriza por lutar pela sua formação continuada, faz da pesquisa a base do ensino, amplia as capacidades e aperfeiçoamento autogestionado de sua prática. Além disso, entende as possibilidades do desenvolvimento do currículo como o meio de pesquisa em contraposição a uma postura técnica limitada à execução; introduz na ação cotidiana uma postura autocrítica. Ademais, a importância da pesquisa no desenvolvimento profissional do professor favorece também o seu crescimento como agente de mudança e, consequentemente, a produção da teoria crítica em educação.

\section{As contribuições das histórias de vida na formação de professores}

Outro processo de formação docente considera como método a reflexão a partir da história de vida, construção do memorial ou da autobiografia, em que a prática e as experiências vivenciadas são fundamentais para a realização da análise. $O$ debate sobre a objetividade e validade científica, do recurso de histórias de vida, tem sido objeto de discussões tanto da Psicologia como na Sociologia.

Nesse sentido, Nóvoa (1992, p. 19) afirma que:

[...] a qualidade heurística destas abordagens, bem como as perspectivas de mudança de que são portadoras, residem em grande medida na 
possibilidade de conjugar diversos olhares disciplinares, de construir uma compreensão multifacetada e de produzir um conhecimento que se situa na encruzilhada de vários saberes.

Além disso, para esse autor, as autobiografias mantêm o sujeito orientado para os temas nos quais a sociologia está interessada e são advindas da história individual de relações com a vida escolar, o conhecimento, os professores e o aprendizado.

Os pressupostos fundamentais com relação às possibilidades dos textos autobiográficos vinculam-se à possibilidade de compreender a metodologia de formar professores, considerando processos reflexivos sobre sua própria memória, percebendo como esta memória pode conter as "transações passadas com a instituição escolar". Ao longo de sua vida, "o sujeito constrói o seu saber ativamente, num processo que se faz por avanços e recuos construindo relações específicas com o saber e o conhecimento que acabam por se encontrar no cerne da identidade pessoal" (NÓVOA, 1992, p. 20). Trata-se de produção de sentidos sobre as experiências de vida, que se relacionam com o processo de formação.

Nos cursos de formação de professores, essa dimensão pode ser potencializada pelas experiências de vida diretamente relacionadas com o processo de formação, pois o futuro professor, durante sua vida escolar, foi objeto da ação de muitos professores, e sua ação profissional será trabalhar com o saber que será adquirido pelos seus alunos em formação. Dessa forma, analisar as histórias de vida possibilita aos indivíduos se aperfeiçoarem, contextualizarem o presente, situarem os acontecimentos ao longo do desenvolvimento profissional. Explica por que fazemos o que fazemos, oferece uma oportunidade de reapreciação, sugere possibilidades de mudança, revela as tendências temporariamente submersas. É um exame detalhado do cotidiano: a busca pela satisfação profissional. As histórias de vida nunca são as mesmas. O essencial da formação reside no processo.

Nóvoa (1992) aponta algumas referências na construção de história de vida:

1. Contexto familiar: como o lugar que marca o processo de autonomização as pessoas que exercem influência são evocadas nos momentos decisivos; este processo relacional tem semelhanças com o processo de socialização.

2. Processo de escolarização: os professores, os colegas, os acontecimentos fracasso e sucesso que condicionam às decisões posteriores. 
3. Vida profissional: valorização da carreira, responsabilidade pelos erros e pelas decisões, as situações relacionais - significação alta.

Em suma, os processos de reflexão possibilitam a construção da autonomia do sujeito, sua responsabilização e interiorização de valores e significados. Os procedimentos incluem discussões em grupo entre os professores responsáveis pelo processo: a busca de eixos articuladores recorrentes no grupo que possam ser, de algum modo, significativos. Organização de um quadro de recorrências e ressonâncias para propiciar oportunidades para que as pessoas situem as suas histórias de vida e as decisões profissionais.

\section{Consideração Finais}

Depreende-se, a partir do conjunto de discussões teóricas realizadas neste artigo, que a formação continuada de professores é uma exigência para os tempos atuais, pode-se afirmar que ela acontece em continuum, tendo como preocupação a instrumentalização para a prática docente, para atuar no mundo e no mercado de trabalho. Uma das sinalizações desta pesquisa é que a formação continuada em serviço no locus da escola pode contribuir para que exista um conjunto de ações voltadas à formação do professor, mas, sobretudo, haja uma progressividade do que o professor faz do seu trabalho, das suas práticas, dos seus saberes acumulados no exercício da docência e nas suas próprias investigações teóricas. Além disso, ele passa a enxergar a possibilidade de desenvolvimento profissional centrada na escola enquanto instituição de trabalho.

Ressalta-se que as três atuais tendências de modalidades dos processos de formação continuada de professores - reflexão na ação, pesquisa e história de vida - podem contribuir para a melhoria da prática docente. Refletir sobre as questões que envolvem a formação continuada de professores nunca será um foco esgotado, por isto considera-se que este estudo poderá contribuir para as instituições escolares, uma vez que elas, via de regra, encontram-se em processo de melhoria na qualidade do ensino, bem como não podem perder de vista a sua responsabilidade social e educacional.

Por fim, as possibilidades abertas por este trabalho certamente suscitarão novas 
pesquisas, novas descobertas, outras construções, que levantarão novos problemas. Eles serão subsidiados pelas ideias e diretrizes aqui desenvolvidas, mas abrirão outras lacunas e contradições; buscarão nós e ligações com outros conceitos e teorias. Dessa forma, isso representa o desafio para sobrepujar os conflitos e os desequilíbrios e atingir um novo patamar de desenvolvimento acerca do campo de investigação da formação continuada de professores.

\section{Referências}

ANDRÉ, M. E. D. A. A pesquisa sobre formação de professores no Brasil 1990-1998. In: CANDAU, V. M. F. (Org.), Ensinar e aprender: sujeitos, saberes e pesquisa. Rio de Janeiro: DP\&A, 2000. p. 83-99.

BERNARDO, W. M.; NOBRE, M. R. C.; JATENE, F. B. A prática clínica baseada em evidências. Parte II: buscando as evidências em fontes de informação. Rev Assoc Med Bras., v. 50, n. 1, p. 104-108, 2004.

BICUDO, M. A. V. A Formação do Professor: Um Olhar Fenomenológico. In: (Org.), Formação de Professores? Da incerteza à compreensão. Bauru: EDUSC, 2003. p. 7-46.

BRASIL. Decreto no 6.755 de 29 de janeiro de 2009. Institui a Política Nacional de Formação de Profissionais do Magistério da Educação Básica, disciplina a atuação da Coordenação de Aperfeiçoamento de Pessoal de Nível Superior. Diário Oficial da República Federativa do Brasil, Brasília, DF, 30 jan. 2009, p. 1. Disponível em: <http://www.planalto.gov.br/ccivil_03/_ato2007-2010/2009/Decreto/D6755.htm>. Acesso em: 09 jun. 2015.

. Ministério da Educação. Secretaria de Educação Profissional e Tecnológica. Leis e Decretos. Lei de Diretrizes e Bases da Educação Nacional, no 9.394, de 20 de dezembro de 1996. Disponível em: <http://www.planalto.gov.br/ccivil_03/leis/I9394.htm>. Acesso em: 30 ago. 2015.

CANÁRIO, R. A Escola: o lugar onde os professores aprendem. Psicologia da Educação, São Paulo, n. 6, p. 9-27, 1998.

CANDAU, V. M. F. A formação continuada de professores: tendências atuais. In: REALI, A. M. R.; MIZUKAMI, M. G. N. (Orgs), Formação de professores: tendências atuais: São Carlos: EDUFSCar, 1996. p. 139-152.

CHARLOT, B. A pesquisa educacional entre conhecimentos, políticas e práticas: especificidades e desafios de uma área de saber. Revista Brasileira de Educação, Rio de Janeiro, v. 11, n. 31, jan.-abr. 2006. p. 7-18.

FREIRE, P. Pedagogia da autonomia: saberes necessários à prática educativa. 9. ed. São Paulo:

Paz e Terra, 1996, (Coleção Leitura). 
GARCIA, M. C. Formación del profesorado para el cambio educativo. Barcelona, EUB, 1995.

GATTI, B. A. Formação continuada de professores: a questão psicossocial. Cadernos de Pesquisa, n. 119, p. 191-204, 2003. Disponível em: $<$ http://www.scielo.br/scielo.php?script=sci_arttext\&pid=S010015742003000200010\&lng=p t\&nrm=iso>. Acesso em: 06 set. 2015.

GATTI, B. A.; BARRETO, E. S. S. Professores do Brasil: impasses e desafios. Brasília: UNESCO, 2009.

GEGLIO, P. C. Formação Continuada de Professores e mudança de prática: uma análise a partir da narrativa de professores. Tese (Doutorado em Psicologia) - Pontifícia Universidade Católica de São Paulo, São Paulo, 2003.

GIL, A. C. Métodos e técnicas de pesquisa social. 5. ed. São Paulo: Atlas, 2007.

KUENZER, A. Z. As políticas de formação: A constituição da identidade do professor sobrante. Educação e Sociedade, ano XX, n. 68, p. 163-183, dez. 1999.

LIBÂNEO, J. C. Reflexividade e formação de professores: outra oscilação do pensamento pedagógico brasileiro? In: PIMENTA, S. G.; GHEDIN, E. (Orgs.), Professor reflexivo no Brasil: gênese e crítica de um conceito. São Paulo: Cortez, 2002. p. 53-80.

LIMA, M. S. L. A formação contínua do professor nos caminhos e descaminhos do desenvolvimento profissional. Tese (Doutorado em Educação) - Universidade de São Paulo, São Paulo, 2001.

MARIN, A. J. Educação Continuada: Introdução a uma análise de termos e concepções. Cadernos Cedes, n. 36, p. 13-20, 1995.

MAZZEU, F. J. C. Uma proposta metodológica para a formação continuada de professores na perspectiva histórico-social. Cadernos Cedes, v. 19, n. 44. p. 59-72, 1998. Disponível em: $<$ http://www.scielo.br/scielo.php?script=sci_arttext\&pid=S010132621998000100006\&lng=p t\&nrm=iso $>$. Acesso em: 06 set. 2015.

NÓVOA, A. Concepções e práticas da formação contínua de professores: In: . (Org.), Formação contínua de professores: realidade e perspectivas. Portugal: Universidade de Aveiro, 1991. p. 15-38.

Vida de professores. Porto: Porto Editora, 1992.

Formação de professores e trabalho pedagógico. Lisboa: Educa 2002.

Professores: imagens do futuro presente. Lisboa: Educa, 2009.

PERRENOUD, P. Práticas pedagógicas, profissão docente e formação. Perspectivas sociológicas. Lisboa: Dom Quixote, 1993.

PIMENTA, S. G. Professor reflexivo: construindo uma crítica. In: PIMENTA, S. G.; GHEDIN, E. (Orgs.), Professor reflexivo no Brasil: gênese e crítica de um conceito. São Paulo: Cortez, 2002. p. 17-52.

ROMANOWSKI, J. P. As licenciaturas no Brasil: um balanço das teses e dissertações dos anos 90. Tese (Doutorado em Educação) - Universidade de São Paulo, São Paulo, 2002. 
ROTHER, E. T. Revisão sistemática x revisão narrativa. Acta Paul Enferm. v. 20, n. 2, p. 5-6, 2007.

SACRISTÁN, G. Os professores como planejadores. In: SACRISTÁN, G.; GÓMEZ, P. A. I. (Orgs.), Compreender e transformar o ensino. 4. ed. São Paulo: Artmed, 1998. p. 271-293.

SANTOS, L. L. C. P. Dilemas e perspectivas na relação entre ensino e pesquisa. In: ANDRÉ, M. (Org.), O papel da pesquisa na formação e na prática dos professores. Campinas, SP: Papirus, 2001. p. 11-26.

SCHÖN, D. A. Formar professores como profissionais reflexivos. In: NÓVOA, A. (Org.), Os professores e a sua formação. Lisboa: Dom Quixote, 1992. p. 77-91.

SOARES, M. B. As pesquisas nas áreas específicas influenciando o curso de formação de professores. Cadernos ANPEd, Rio de Janeiro, n. 5, p. 103-118, 1993.

ZEICHNER, K. M. A formação reflexiva de professores: idéias e práticas. Lisboa: Educa, 1993.

Recebido em: 06/01/2018

Aprovado em: 16/03/2018 